Session 3215

\title{
Digital Imaging Activities for Civil Engineering Students
}

\author{
Kauser Jahan, Shreekanth Mandayam, Beena Sukumaran and Yusuf Mehta \\ Rowan University, College of Engineering \\ Glassboro, NJ 08028
}

\begin{abstract}
Digital imaging is an exciting field with applications in all areas of engineering. It currently represents one of the major research and development focus areas with sales exceeding 10 billion dollars per year. The technology has also become a part of our daily lives through televisions, cameras, scanners and medical X-rays. Engineers play an important and expanding role in this exciting field, yet undergraduate engineering students in civil and environmental engineering are rarely exposed to digital imaging through their coursework. The College of Engineering at Rowan University received funding from NSF to integrate digital imaging technology (DIT) in our undergraduate engineering curriculum. Faculty from all engineering disciplines with expertise in DIT participated in this exciting project to develop hands-on experiments for undergraduate engineering students. Experiments developed were such that all engineering disciplines would benefit from the endeavor. Certain digital imaging experiments have generated a lot of excitement in the Civil and Environmental Engineering program as many of the laboratory experiments are extremely traditional and are required to follow standard methodology. It is anticipated that other institutions will adopt the experiments that were developed as all educational materials are provided through a dynamic website.
\end{abstract}

\section{Introduction}

The College of Engineering at Rowan University received funding to establish a Digital Imaging (DI) laboratory and develop digital imaging course material by a team of Rowan faculty. Faculty with expertise in digital imaging technology from all engineering disciplines have developed hands-on experiments that can be readily used by various engineering and science disciplines. Funding was obtained from the National Science Foundation to purchase equipment to strengthen our DI laboratory and also to develop innovative educational material. Attention was given to develop material appropriate for a broad audience that includes K-12 educators/students and college students from science and engineering.

The College of Engineering at Rowan University encourages faculty to integrate innovative teaching methods to expose students to contemporary topics. One such topic that is gaining momentum and popularity is digital imaging. This is a rapidly growing field with numerous applications ranging from consumer products, health services to research in academia. The new

Proceedings of the 2005 Annual American Society for Engineering Education Conference. Copyright (C) 2005, American Society for Engineering Education 
generation of students are extremely familiar with imaging techniques common in biotechnology such as X-rays, CT scans, MRI, mamograms and ultrasound. Digital images now allow scientists and engineers to obtain accurate, minute details that can easily be missed by the human eye. Until recently, digital still photography and digital video technology were both costly and complex. But now, a number of new products have changed things for the better, and teachers and administrators are taking advantage of the latest technologies to motivate students and to add new skills to the curriculum.

Traditional engineering curriculum like civil and environmental, chemical and mechanical engineering typically do not offer courses in digital imaging. As such DI technology has not been integrated in traditional undergraduate engineering education formally. Traditionally courses related to digital image processing reside in the Physics and Electrical Engineering curriculum. Undergraduate students in civil and environmental, chemical and mechanical engineering are typically never exposed to digital imaging through their traditional coursework or laboratories. Some students may get exposure through a research project in their senior years. The Civil and Environmental Engineering laboratories are extremely traditional with experiments that have to conform to ASTM or EPA standards. This paper describes certain experiments that were developed to bring innovative technology and excitement to our Civil and Environmental Engineering Curriculum.

\section{Objectives}

The specific goals of this project as outlined in the NSF proposal are to:

- Provide specialized skills and training to students in the emerging field of digital imaging technology,

- Demonstrate the application of various imaging techniques in the characterization and visualization of the microstructure of different engineering materials,

- Expose students to the state of the art technologies in image acquisition, processing and analyses,

- Develop novel hands-on experiments using various imaging techniques that can be readily used by different engineering disciplines,

- Ensure the highest quality SMET education by improving existing undergraduate courses, curricula and laboratories by developing hands-on innovative experiments, and

- Dissemination of information through web pages, CD-ROMs and seminars for targeted audiences such as K-12 outreach, new faculty preparation and teacher/technician training.

\section{Project Implementation}

Faculty with expertise in DI technology participated from all four engineering disciplines (civil, chemical, electrical and mechanical) ${ }^{1-4}$. The College of Engineering at Rowan University has a brand new engineering program that is highly ranked nationwide ${ }^{5-10}$. A digital imaging laboratory has been set up in the electrical and computer engineering department. The College

Proceedings of the 2005 Annual American Society for Engineering Education Conference. Copyright $($ C 2005, American Society for Engineering Education 
has obtained microscopes, digital cameras, X-ray Scanners and software for the project. Equipment acquisition has been completed and experiment development is still in progress. The equipment holding is indicated in Table 1.

Table 1: Current DIT Equipment Holding at the College of Engineering

\begin{tabular}{llll}
\hline $\begin{array}{l}\text { Civil and } \\
\text { Environmental }\end{array}$ & Chemical & $\begin{array}{l}\text { Electrical and } \\
\text { Computer }\end{array}$ & Mechanical \\
\hline Handheld GPS & $\begin{array}{l}\text { 40X Nikon 120 } \\
\text { Inverted Phase } \\
\text { Contrast } \\
\text { Microscope }\end{array}$ & Ultrasound Imaging & $\begin{array}{l}\text { High Speed Video } \\
\text { Camera }\end{array}$ \\
$\begin{array}{l}\text { Digital Video } \\
\text { Camera (Lowend) }\end{array}$ & SEM & Digital Video \\
$\begin{array}{l}\text { FEM Code } \\
\text { ABAQUS }\end{array}$ & Magnetic Imaging & $\begin{array}{l}\text { Camera- Professional } \\
\text { Thermal (IR) Camera }\end{array}$ \\
$\begin{array}{l}\text { Optical } \\
\text { CT Scanner }\end{array}$ & & & $\begin{array}{l}\text { Image Capture } \\
\text { Hardware }\end{array}$ \\
& & PCBird & Video Editing \\
\hline
\end{tabular}

A dynamic website has been setup with the following URL:

http://users.rowan.edu/ jahan/imaging/Webpage/index.htm. The web page has links to detailed descriptions of the experiments and also pictures of the equipment at hand (DI Equipment). Useful links such as tutorials on digital imaging are also available.

A K-12 outreach module on digital imaging has also been developed. This is also available on the web under the K-12 outreach link. The module on digital imaging is offered for our middle school workshop for girls titled "Attracting Women into Engineering". Participants are introduced to the basics of digital imaging such as number and colors. Digitizing of mammograms and the identification of radio dense tissue through imaging is also introduced to the participants as a mechanism for detecting breast cancer in women.

\section{Experiments}

A number of experiments have been developed to expose students to digital imaging. The experiments were developed by engineering juniors/seniors under the supervision of graduate students and participating faculty. Eight modules have been developed to date to expose students to DI experiments. Experiments developed help students understand the applications of digital imaging to their relative area of expertise. Each experiment can be used by various science and engineering disciplines. For example, a thermal imaging experiment to detect cracks in metal pipes was developed by our Mechanical Engineering faculty for demonstrating application of thermal imaging. However this experiment is a perfect fit for our Structures and Civil Engineering Materials laboratory and course.

Proceedings of the 2005 Annual American Society for Engineering Education Conference. Copyright (C) 2005, American Society for Engineering Education 
Some simple activities have been developed for freshman courses to expose them to DI applications. The experiments that were developed are indicated in Table 2.

Table 2: Digital Imaging Experiments

\begin{tabular}{ll}
\hline$\#$ & Experiment Title \\
\hline 1 & $\begin{array}{l}\text { Visualizing Pollutant Diffusion and Determining Pollutant Diffusion Speed from } \\
\text { Analyzing Sequential Images }\end{array}$ \\
2 & $\begin{array}{l}\text { Analysis of Internal Structure of Composite Materials and Prediction of } \\
\text { Performance }\end{array}$ \\
3 & Digital Imaging in Biotechnology-Applications in Mammography \\
4 & Biomedical Image Processing Applications \\
5 & Ultrasonic Imaging System for Detecting Cracks in Metal and Concrete Pipes \\
6 & Image Compression using Multi-resolution Wavelet \\
7 & Applications of Thermal Imaging for Analysis \\
8 & Imaging applications in Fluid Mechanics (Under Development) \\
9 & Miscellaneous Experiments for Freshmen \\
\hline
\end{tabular}

Experimental modules one, two, five and seven have major applications in Civil and Environmental engineering. Courses that can be readily impacted by these modules in our Civil and Environmental engineering program are shown in Table 3.

Table 3: General and Core Courses in Civil Engineering that are Impacted

\begin{tabular}{ll}
\hline General & Civil and Environmental Engineering \\
\hline Freshman Clinic (9) & Fate \& Transport Processes $(1,2,5\}$ \\
Engineering Materials $(2,5,7)$ & Wastewater Treatment $(1)$ \\
Fluid Mechanics $(8)$ & Water Treatment $(1,2)$ \\
Junior Clinics & Civil Engineering Materials $(2,5,7)$ \\
Senior Clinics & Transportation Engineering $(2,5,7)$ \\
Mechanics $(2,5)$ & Geotechnical Engineering $(1,2,5,7\}$ \\
\hline
\end{tabular}

\section{Experiment Descriptions}

Visualizing Pollutant Diffusion and Determining Pollutant Diffusion Speed: Particle or pollutant diffusion is an integral part of chemical and environmental engineering courses. Currently pollutant diffusion is demonstrated in the Fate and Transport of Organic Compounds course as a visual experiment using colored dyes. The objectives of this module are (a) to

Proceedings of the 2005 Annual American Society for Engineering Education Conference. Copyright (C) 2005, American Society for Engineering Education 
introduce digital imaging methods to visualize pollutant diffusion and (b) attainment of pollutant diffusion speed from analyzing sequential images. A sandbox experiment has been developed to visualize the movement of blue dye through clean sand and sand inoculated with bacteria.

Analysis of Internal Structure of Composite Materials and Prediction of Performance: The mechanical behavior of civil engineering materials has been understood on a macro-level, but the behavior becomes an approximation especially when dealing with composite materials like cement concrete, asphalt concrete, aggregates and soils. Digital microscopes and X-ray tomography along with an automated image analyzer have been used to capture the internal structure distribution of common civil engineering materials. The purpose of this module is to correlate internal structure distribution to common material properties like strength and modulus.

Ultrasonic Imaging System for Detecting Cracks in Metal and Concrete Pipes: Experiments have been developed using ultrasound-imaging techniques for detecting cracks in metal and concrete pipes. Students can obtain images of metal and concrete specimens with defects and then use image-processing algorithms to characterize and predict defects.

Applications of Thermal Imaging for Analysis: Thermal imaging can be applied to human systems to examine heat distribution and dissipation, or a test object may be artificially heated using resistive or optical means to examine the object for damage or defects. An experiment has been developed for pipeline inspection, damage in glass-fibered reinforced composite panels, and material defects in metals, ceramics and polymers.

\section{Example of DI use in a Freshman Class}

Freshman Clinic classes expose students to various engineering materials and chemicals through laboratory modules. We have introduced some hands-on simple activities for the students so that they can acquire digital images of common engineering chemicals and materials. Materials include table salt, sand and lava rock. The activity is simple yet extremely informative. Students can get an idea of the structural shape, presence of pores and impurities.

The images are taken at a $32 \mathrm{X}$ magnification (3.2X objective, $10 \mathrm{X}$ eyepiece) with a M101A microscope from Gaertner Scientific. The camera used is a QICAM 12-bit from Q-Imaging Corporation. Images obtained for table salt, sand and lava rock are shown in Figure 1 along with the equipment setup in Figure 2.
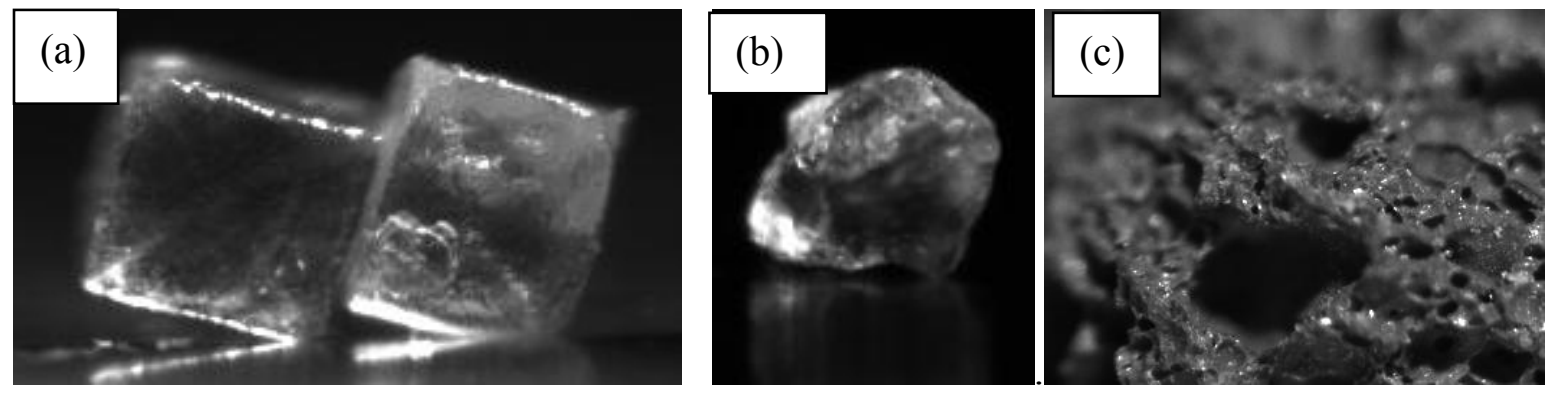

Figure 1: Digital Images of (a) Table Salt (b) Sand $\quad$ (c) Lava Rock

Proceedings of the 2005 Annual American Society for Engineering Education Conference. Copyright (C) 2005, American Society for Engineering Education 


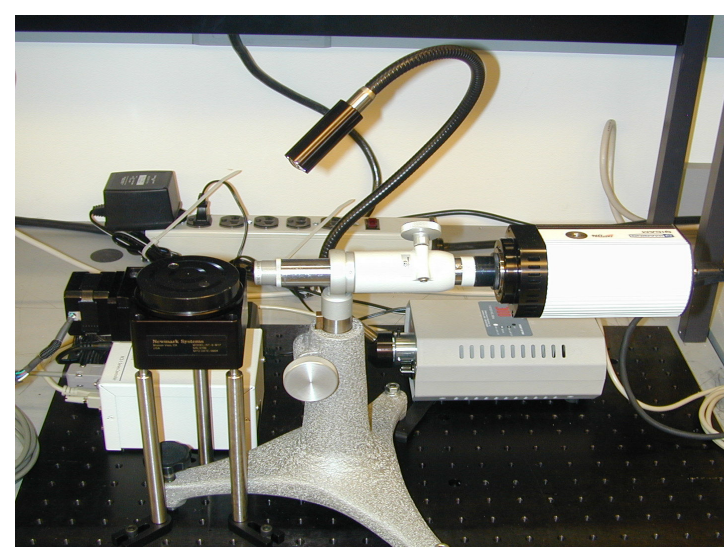

Figure 2: Digital Imaging Equipment for acquiring 3-D images

These simple exercises allow students to better visualize material properties and structure without always relying on pictures illustrated in a textbook. This allows the course content to come alive for the students as they themselves are involved in the acquisition of an image of a material to better understand the material structure and properties.

\section{Impact and Dissemination}

Impact of the experiments will be assessed via student surveys and course evaluations. Formative evaluations will be conducted through student surveys (pre- and post) and technical quizzes at the start and completion of each module as it is implemented in the curriculum in various courses. Students will be required to assess their interest level in the material, adequacy of background knowledge, relevance to course material and the impact of the module in enhancing their understanding and knowledge. Additional comments will be requested for improvement of the modules. Assessment activities are in progress. The information dissemination activities have been impressive. We have a number of publications and presentations ${ }^{11-15}$, a dynamic website and have integrated DI for K-12 outreach.

\section{Conclusions}

This DIT project allows Rowan engineering faculty and students to integrate new technology into the current engineering courses. The project has allowed the development of digital imaging curriculum and a digital imaging laboratory/studio to facilitate the use of DIT in teaching and learning activities for undergraduate engineering students. K-12 outreach has also been an exciting component of the DIT project. The colors and numbers module is very well received by middle school girls. Currently two more modules are still being developed in the area of nanotechnology and thermodynamics. The web is being used to disseminate information and allowing other institutions to adopt the developed experiments. 


\section{Acknowledgement}

This project is being funded by a grant from the National Science Foundation (NSF DUE \#0231033) and Rowan University. We would like to offer our sincere appreciation to the engineering clinic students at the College of Engineering for their support in developing the experiments.

\section{References}

1. J. Neyhart, M. Kirlakovsky, L. Coleman, R. Polikar, M. Tseng and S. Mandayam, "Automated Segmentation and Quantitative Characterization of Radiodense Tissue in Digitized Mammograms," Proceedings of the 28th Annual Review in Progress of Quantitative NDE, Brunswick, ME, USA, Aug. 2001.

2. Neyhart, M. Ciocco, R. Polikar, M. Tseng and S. Mandayam, "Dynamic Segmentation of Breast Tissue in Digitized Mammograms using the Discrete Wavelet Transform," Proc. of the 23rd Annual International Conference of the IEEE Engineering in Medicine and Biology Society, Istanbul, Turkey, Oct. 2001.

3. S. Mandayam, J. L. Schmalzel and A. J. Marchese, "Nondestructive evaluation of aircraft skin: Product design and development in the sophomore engineering clinic," Proceedings of the Frontiers in Education Conference, Phoenix, 1998.

4. S. Mandayam, K. Jahan and D. B. Cleary, "Ultrasonic based defect characterization in wastewater concrete pipelines using invariance transformation techniques," Proceedings of the 73rd Annual Conference and Exposition on Water Quality and Wastewater Treatment (WEFTEC), Anaheim, CA, October 14-18, 2000.

5. Marchese, A. J., Constans, E., Dahm, K., Hollar, K., Hutto, D., Johnson, F., Sun, C. von Lockette, P., Kadlowec, J., Cleary, D., and Sukumaran, B. (2001). The Sophomore Engineering Clinic I: Integrating Statics, Solid Mechanics and Product Development in a Sophomore Level Design Course. ASEE Annual Meeting, Albuquerque, NM.

6. Johnson, F. S., Hutto, D., Dahm, K., Marchese, A. J., Sun, C., Constans, E., Hollar, K. and von Lockette, P. (2001). An Investigation into Interdisciplinary Team Teaching in Writing and Engineering: A MultiYear Study. ASEE Annual Meeting, Albuquerque, NM.

7. Jahan, K. and R.A.Dusseau (1998) Environmental Design for Multidisciplinary Teams, Proceedings of the 1998 Annual Conference of ASEE, Seattle, Washington, June 28-July 1.

8. Jahan, K. et al., (1997d) The Rowan engineering program: Preparing Students for the Future Marketplace, Zone I Fall ASEE Conference, Wilmington, De, Oct. 1997.

9. Newell, J. A., Marchese, A. J, Ramachandran, R. P., Sukumaran, B. and Harvey, R. (1999). Multidisciplinary Design and Communication: A Pedagogical Vision. International Journal of Engineering Education. Vol 15, No. 5, pp. 376-382.

10. Schmalzel, J.L., A.J. Marchese, J. Mariappan, and S. Mandayam, "The engineering clinic: A four-year design sequence," $2^{\text {nd }}$ An. Conf. of Nat. Collegiate Invention and Innovation Alliance, Washington, D.C., March 13-15, 1998.

11. Kauser Jahan, John Chen, Shreekanth Mandayam, Robert Krchnavek, Beena Sukumaran, Yusuf Mehta, Jennifer Kadlowec, Paris von Lockette, Robi Polikar (2005) Digital Imaging for Engineering Students, NSF Grantees Poster Presentation, 2005 ASEE Annual Conference, Portland, OR.

12. Kauser Jahan, John Chen, Shreekanth Mandayam, Robert Krchnavek, Beena Sukumaran, Yusuf Mehta, Jennifer Kadlowec, Paris von Lockette, Robi Polikar (2004) Digital Imaging Experiences for Engineering Students, Proceedings of the Mid-Atlantic ASEE Fall Conference, Washington D.C.

Proceedings of the 2005 Annual American Society for Engineering Education Conference. Copyright (C) 2005, American Society for Engineering Education 
13. Kauser Jahan, John Chen, Shreekanth Mandayam, Robert Krchnavek, Beena Sukumaran, Yusuf Mehta, Jennifer Kadlowec, Paris von Lockette, Robi Polikar (2004) Digital Imaging Experiments for Engineering Students, Proceedings of the ASEE Annual Conference, Salt Lake City, UT.

14. Kauser Jahan, John Chen, Shreekanth Mandayam, Robert Krchnavek, Beena Sukumaran, Yusuf Mehta, Jennifer Kadlowec, Paris von Lockette, Robi Polikar (2003) Digital Imaging Across the Curriculum, Proceedings of the Mid-Atlantic ASEE Fall Conference, Baltimore, MD.

15. Kauser Jahan, John Chen, Shreekanth Mandayam, Robert Krchnavek, Beena Sukumaran, Yusuf Mehta, Jennifer Kadlowec, Paris von Lockette, Robi Polikar (2004) Digital Imaging Across the Curriculum”, World Transactions on Engineering and Technology Education, Vol. 3, No. 2, pp 173-300.

\section{Biography}

Dr. Kauser Jahan is an Associate Professor of Civil and Environmental Engineering at Rowan University, Glassboro, New Jersey. She completed her Ph.D. studies in the Department of Civil and Environmental Engineering at the University of Minnesota, Minneapolis in 1993. Dr. Jahan is a registered Professional Civil Engineer in Nevada and is actively involved in environmental engineering education and outreach for women in engineering. Her research interests include biodegradation of petroleum compounds and surfactant enhanced remediation of slightly soluble organic compounds.

Dr. Shreekanth Manadayam's research expertise is in digital signal and image processing and electromagnetic nondestructive evaluation. He has been extensively involved in the design and development of nondestructive evaluation systems, both as part of his graduate work and as a faculty member at Rowan University. He has established a thriving NDE laboratory at Rowan along with Drs. Jahan and Chen with sponsorship from NSF, US Army TACOM and the Water Environment Research Foundation. His present research interests lie in the area of medical image processing.

Dr. Beena Sukumaran is an Associate Professor of Civil and Environmental Engineering at Rowan University, Glassboro, New Jersey. She obtained her Ph.D. from Purdue University in the School of Civil Engineering with particular emphasis in Geotechnical Engineering. Her research interests include evaluating the performance of suction caissons in different soil conditions, effect of inherent particle characteristics on liquefaction potential, pavement analysis, fuzzy set applications in geotechnical engineering and use of the discrete element method to investigate the interaction forces acting on particles.

Dr. Yusuf Mehta is an Assistant Professor of Civil and Environmental Engineering. He has extensive experience in pavement materials characterization. Dr. Mehta has been involved with several projects with the Departments of Transportation in various states (Florida, New Jersey, Rhode Island, Wisconsin).

Proceedings of the 2005 Annual American Society for Engineering Education Conference. Copyright $(\mathrm{C} 2005$, American Society for Engineering Education 